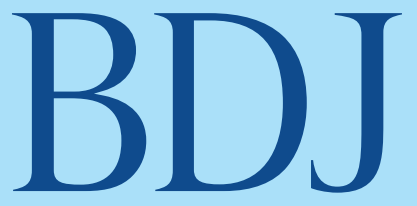

RESEARCH INSIGHTS

FOR ANOTHER VIEW

- Research insights from across the BDJ Portfolio

- Providing busy readers with valuable context including article summaries and expert commentary

Catch up here:

http://bit.ly/BDJResearchlnsights
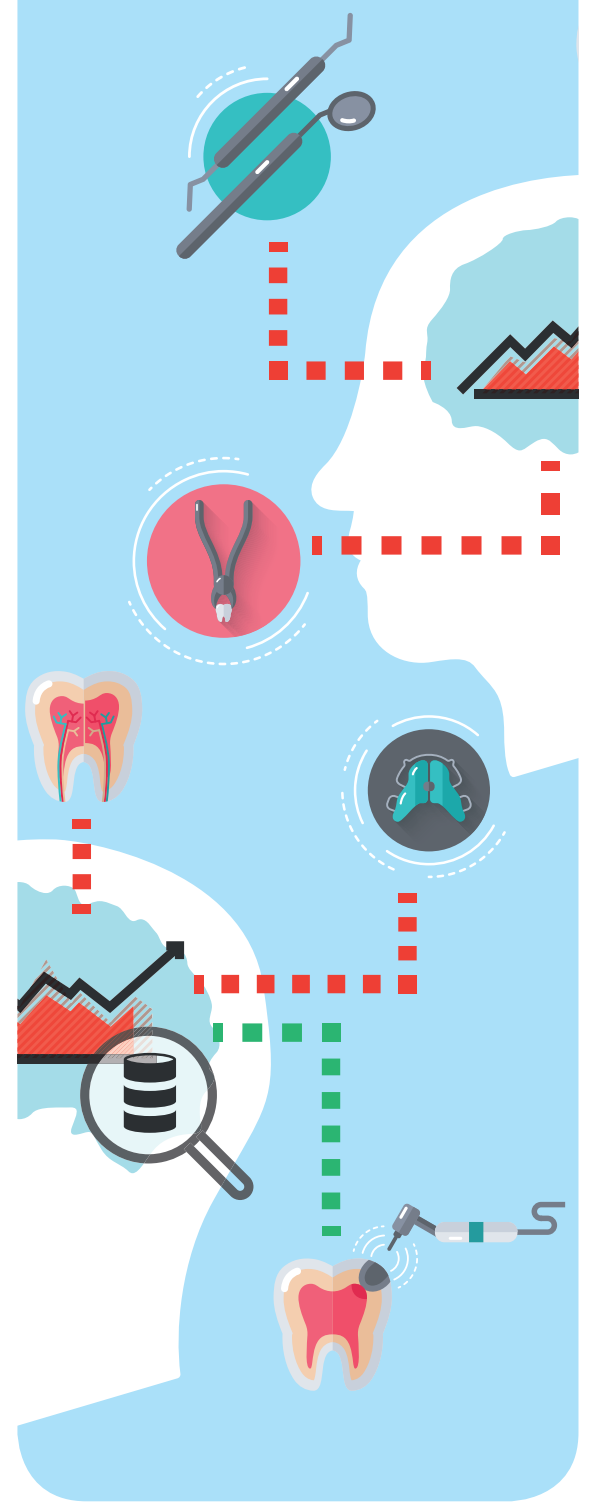

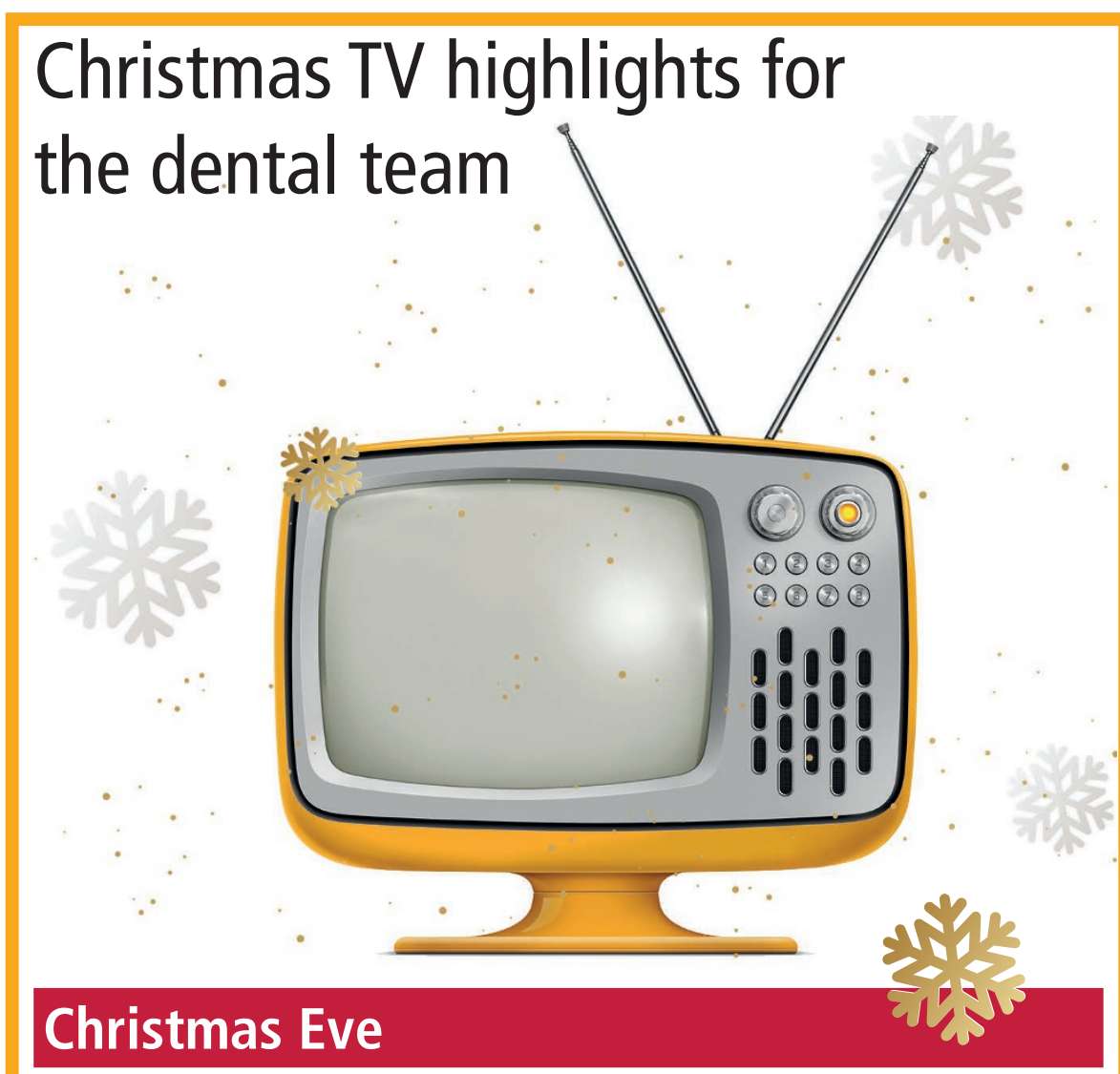

7:30 pm Coronation Street

Steve regrets not having his wisdom tooth out (as advised by his dentist in July 2015), and suffers an agonising run up to Christmas trying to find an emergency dentist in Manchester. A power cut in the Rovers causes much hilarity as Ken loses his lower retainer in a pint of bitter.

\section{Christmas Day}

9 am Christmas Carols Live from the General Dental Council
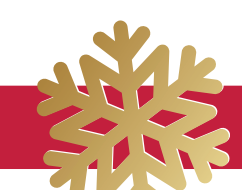

Join the GDC team as they sing such classics as 'The twelve days until you have to get your declared CPD declaration in' and 'I'm dreaming of a white Christmas (but no illegal bleaching)'

\section{Boxing Day}

2 pm A Christmas Carol

A festive classic retold as Dave (a dentist from Hull) is visited by three ghosts:

The Ghost of Christmas Past who revisits his university days in the 1980s when he cheated in a dental materials exam and never returned the skull he 'borrowed' from the anatomy department for a Halloween prank.

The Ghost of Christmas Present reminds him how bad he is at making dentures (Mrs Jones is on her fourteenth ease appointment). Will Dave finally go on that refresher course?

The Ghost of Christmas Yet To Come brings the future to mind, more CQC inspections and enhanced CPD/personal development plans (good job Dave is well stocked up on mulled wine).

Merry Christmas!

By Mike O'Reilly 